\title{
Challenges Facing the Application of IoT in Medicine and Healthcare
}

\author{
Muhammad Adnan Khan \\ Gachon University, South Korea, madnankhan@ncbae.edu.pk
}

\begin{abstract}
Among all the functions of the Internet of Things, healthcare applications are the most important. The internet of Things has played a vital role in the sharing of various medical resources making it an essential factor in the field of medicine. Without the applications, it may become challenging for the medical practice to achieve some objectives. Today, information is shared freely across different networks, making it easy for practitioners and institutions to work with the available resources and deliver on the medical needs of the society. IoT has made it possible to offer smart and effective healthcare services to people. The application of smart sensors is one of the factors that has contributed to effective management of healthcare needs in the society. Wearable devices can be used to track different issues within the body. Some can be embedded to monitor different functions of the body to ensure there is effectiveness in the way medical services are delivered to such patients. The information collected in such manner, can be analyzed, aggregated and mined to do the early prediction of diseases. Processing algorithms play a vital role in helping practitioners in developing personalized treatment, which makes healthcare more economical. Apart from analyzing the effectiveness of IoT in healthcare, challenges will be discussed in this study and how they impact medicine.
\end{abstract}

Keywords - Internet of Things, Machine Learning, smart devices

\section{INTRODUCTION}

The world population is increasing tremendously. An improved quality of life has led to the development of highly effective means through which various aspects of the environment which encourage the improvement of the life of people in the world. However, there are limited resources in various sectors and technology has come in to ensure effectiveness is achieved in these sectors to ensure the little resources are helpful in the society. The increasing population, 
especially in the urban regions has led to the build-up of astounding pressure on the available resources [1]. The medical sector is one of the areas that has felt the pressure due to increased demand of the medical services. Despite the increasing expansion of healthcare facilities, the population still has a great impact on how the facilities work and the quality of services they offer to the public [2]. The massive pressure has triggered the development and application of various technological solutions necessary in ensuring effectiveness is restored in the medical and healthcare sector[3].

There is a rise in medically challenged people in the society. Remote medical services is increasingly becoming part of our lives where patients can be attended in their remote locations. A rise in interest in wearable medical devises has been witnessed in the recent past [4]. People are increasingly becoming aware of their health and how they can handle different issues effectively for them to achieve their medical goals meant to develop an effective means through which they can handle issues regarding their healthcare needs [5] The advanced technology of wearable devices is essential in the collection of data, management, and monitoring of the body functions [6] The application of technology in this field is irresistible since there is a need to develop a sustainable healthcare sector.

The Internet of Things (IoT) offers a rising technology that is essential in ensuring more affordable, low-cost healthcare services are available for patients [7]. The smart devices can either be worn or embedded in the body and they play a vital role in sending signals about the nature of the body and effects of various conditions [8]. The devices enable seamless networking between the patients, medical devices and physicians. The sensors will record signals in a continuous manner, they are then correlated with the essential physiological parameters and communicated over the wireless network. The data collected is stored, analyzed and used against the existing health records that have been taken before [9]. Physicians are able to conduct more advanced prognosis and encourage early treatment interventions meant to ensure the patient receives the most effective medical services early enough to mitigate the risk of adverse outcomes [10] The machines are essential in the sense that even when the doctor is not available, they help in predicting the health issues that a patient may be having[11]. Through effective machine learning techniques, the devices have been equipped with abilities that can be used to enhance the delivery of medical services by giving suggestions for the medication that should be administered [12]. 
The nature of this progressive technology is that, it will have impact on everyone in monitoring health and cutting down on the healthcare expenses that people may be having. This paper develops the technological and economic views for the comfort of patients and delve more into the challenges that face the application of IoT in the medical field [13]. This is one of the ways through which solutions to the challenges can be sought. Understanding the nature of IoT and its impact on the medical sector is essential. Deep analysis of the challenges this important aspect faces in the field of medicine and healthcare is also important because it helps in defining some of the issues in healthcare which can easily be resolved through the engagement of effective technologies [14].

\section{BACKGROUND}

The Internet of Things has been developing over time and its importance has been realized in different sectors[15], [16], [17]. The medical and healthcare sector is also one of the beneficiaries of these technological developments [18]. This is an important aspect of the technology that should be utilized in the delivery of effective healthcare services in the society [19]. The healthcare sector is facing different challenges that require the application of technology to enable it to work effectively [20]. Developing accurate technologies for the purposes of healthcare improvement has faced challenges because there are many needs that have to be satisfied[21]. Developing an IT-based solution for all these needs can be challenging. However, there are milestones that have been achieved by the application of IoT technologies in the healthcare systems [22].

The IoT and machine learning technologies have been developed and have been on the rise across different industries [23]. The medical industry is benefiting greatly from these technologies because there are solutions that have been developed over time which have an important aspect of delivering organizations from different challenges that they face [24]. However, the implementation of these technologies in the healthcare sector has come with many challenges which solutions have to be sought for them to be managed effectively [25]. IoT has made it possible to offer smart and effective healthcare services to people. The application of smart sensors is one of the factors that has contributed to effective management of healthcare needs in the society. Wearable devices can be used to track different issues within the body. Some can be embedded to monitor different functions of the body to ensure there is 
effectiveness in the way medical services are delivered to such patients [26]. The information collected in such manner, can be analyzed, aggregated and mined to do the early prediction of diseases. Processing algorithms play a vital role in helping practitioners in developing personalized treatment, which makes healthcare more economical [27].

Challenges in implementing IoT in the healthcare sector are evident. Faulty networks and misinterpretation of some of the data and information from the devices can be detrimental to the effective use of the IoT devices [28]. Understanding the challenges is necessary in developing the most effective means through which they can be managed for effectiveness to be achieved in the use of these devices and technologies [29]. Faulty engagements of the technologies can be harmful to the patients because that will lead to the application of ineffective treatment interventions [30].

\section{INDUSTRY DESCRIPTION}

The medical and healthcare industry is growing and expanding services as the world's population also grows [31]. The sector is characterized by many milestones as well as challenges. It is always in need of solutions to solve the healthcare issues that face the society on a daily basis. As the world population grows, so is the demand for healthcare services. The medical and healthcare sector has not been in a position to fully satisfy the needs of people in various societies. However, there are technological solutions that have been developed to ensure there is effectiveness in the delivery of various services [32].

The healthcare sector has embraced technology as one of the ways through which sustainable development can be achieved in the sector. The Internet of Things and machine learning have come in handy to save the industry from the massive pressure that is experienced at different levels of delivering healthcare services in the society [33]. This is an essential factor to consider and develop an effective means through which the technology can be applied in the society and achieve the most desirable results of managing the healthcare needs of the society. The healthcare sector has to develop effectively through having an effective means through which the technology can be incorporated to improve the nature of interactions that patients and practitioners have in this field. Incorporating IoT in the medical field is necessary in understanding various developments in the sector [34]. 
There are differences in the healthcare sector when comparing the developed and the developing world. The developing world experiences more challenges compared to the developed world in the sense that there is a need to develop strategies to be applied in the management of issues relating to the healthcare needs of the society [35]. In the developing world, accessing and affording healthcare services is challenging and that has an effect on how different issues are managed at this level. Quality of healthcare services is also essential and developing an effective means through which the quality can be improved by reducing the workload and the pressure on the local facilities is essential in delivering an effective means through which the issues can be managed effectively [36]. Developing through technology is necessary in ensuring the society has access to affordable and quality medical services because it is through this development that the quality of life of individuals will be improved. The reduced workload on the facilities is vital in the management of healthcare in the society.

\section{LITERATURE REVIEW}

\section{A. Challenges of IoT in Healthcare}

Health monitoring systems have been developed in the recent days. This has been a great development in the field of medicine where there are important aspects of the healthcare systems that have come into play and are aiding the delivery of timely and effective healthcare services. P2P and IoT technologies have been incorporated into the medical system to keep most patients in control. The incorporation led to the development of the smart box [37]. Web real time communication was enhanced in the wearable devices so that real time transmission of data would be achieved. This is one of the ways in which a patient could be controlled through the systems and achieve one of the most effective means through which treatment could be administered. The applications relating to the use of the IoT devices played a vital role in the management of various issues which may have affected the patients.

Portable devices were introduced in the market and this enhanced the mobility of patients. A few drawbacks and security threats were a major factor in this development. The security threats are critical in the delivery of an effective means through which the devices and systems are supposed to work. Security is important especially when a device is known to be of a high value [38]. The patient has to be careful with such a device because it can attract people who may want to take it away due to its value. The devices have been developed with a lot of IoT and 
machine learning technologies which play a vital role in the management of different conditions that patients may portray [39]. This can attract those who may want to steal and resell these devices making it a great challenge for the users.

Prediction challenges are also evident in the system where there are different data sets that can be interpreted differently making it difficult to achieve some goals that have been set. This is an important aspect of the IoT and machine learning technologies [40]. Users are supposed to be trained on how to predict and interpret various data collected by the devices. Inaccurate interpretation of data can lead to faulty analysis and result in the poor delivery of healthcare services in the sector. The sensors can be faulty at times and there is a need to have an effective way of confirming the data that is received from the sensors. A high level of accuracy needs to be embraced in the sector to ensure there is effectiveness in how the data is collected and the sensors deliver accurate information. This is an essential factor in managing different issues effectively in the healthcare sector and having an effective means of handling the issue is vital in managing different issues as they arise in the process of understanding the nature of data that is collected from the sensors [41].

Information security is the other challenge that can affect the effectiveness of utilizing IoT in the healthcare sector. All internet based networks and solutions are exposed to these challenges which can affect the effective delivery of services. It is important to have information security systems in place to protect the device users from possible attacks which may result in alteration of the data that is transmitted from the devices [42]. The information security challenge can be managed through having an effective strategy in place to manage different issues as they arise in the healthcare sector. Information security is vital for all devices that share a network that is internet based [43]). IoT is internet-based and there is a need to understand that the systems are vulnerable and face the risk of information security threats. However, there are measures and strategies that can be employed to ensure effectiveness is achieved in the delivery of medical services based on the IoT systems.

\section{B. System Architecture}

The IoT system has four protocol areas which have different functions and can be used for different purposes for the technology to work effectively. The first is the one that has devices embedded with sensors. It is the physical layer. The second is the network layer that is meant to transmit signals form the sensors to the cloudlets. The cloudlets send this signal to the 
middleware layer that has to store the signal. Finally, in the application layer, analytics and diagnosis process are performed. There are a series of steps that deliver the system's work appropriately.

Data collection and transmission - Patients are given wearable devices which have sensors which have a role of collecting data from the body. The sensors have the ability to measure Electrocardiography (ECG), Temperature, Electromyography (EMG) muscle activity, respiratory rate, and sweating and blood glucose level. These are essential factors to be considered in the process of analyzing various body effects that need treatment [44].

Cloudlet Processing - This is an important process where data can be processed and stored. Mobile phones can be used to assist in the storage of the data. The cloud is also well enhanced to handle some of these issues and it can also be used to store data collected from the devices [45].

Analytics and Prediction - This is the final stage of using data from the devices. Machine learning algorithms are applied in correlating the sensors' parameters and clinical data. Challenges may arise at this point because in the medical field, new measurement tools are often introduced which may not match the required analytical systems that are in place for specific devices. The data from IoT warble sensors are spanned using different visualization methodologies for the effective prediction. Visualization tools are then utilized to give the details and interpretations of the data from sensors [46].

\section{CONCLUSION AND SUGGESTIONS}

The importance of remote health monitoring systems was discussed in this study. Many academic and professional researches have been conducted and the effectiveness of the remote IoT-based solutions have been found to be highly effective in the sustainable development of the healthcare sector. The internet of Things has played a vital role in the sharing of various medical resources making it an essential factor in the field of medicine. Without the applications, it may become challenging for the medical practice to achieve some objectives. Future studies are supposed to cover various issues that affect the delivery of effective services for the purposes of having an effective IoT-based healthcare system. Remote management of patients is becoming a common phenomenon and it is important to have a highly effective means through 
which the issues on healthcare can be managed effectively for the delivery of an effective means of managing the patients without having the challenges highlighted by this study.

\section{REFRENCES}

[1] M. A. M. Afifi, D. Kalra, T. M. Ghazal, and B. Mago, "Information Technology Ethics and Professional Responsibilities," International Journal of Advanced Science and Technology, vol. 29, no. 04, pp. 11336-11343, Dec. 2020, Accessed: Nov. 16, 2021. [Online]. Available: http://sersc.org/journals/index.php/IJAST/article/view/34696

[2] G. Thamilarasu and S. Chawla, "Towards Deep-Learning-Driven Intrusion Detection for the Internet of Things," Sensors 2019, vol. 19, no. 9, p. 1977, Apr. 2019, doi: 10.3390/S19091977.

[3] T. M. Ghazal, M. K. Hasan, M. T. Alshurideh, H. M. Alzoubi, M. Ahmad, S. S. Akbar, B. al Kurdi, and I. A. Akour, "IoT for Smart Cities: Machine Learning Approaches in Smart Healthcare-A Review," Future Internet, vol. 13, no. 8, p. 218, Aug. 2021, doi: 10.3390/FI13080218.

[4] R. Parada, J. Melià-Seguí, and R. Pous, “Anomaly Detection Using RFID-Based Information Management in an IoT Context," Journal of Organizational and End User Computing, vol. 30, no. 3, pp. 1-23, Jul. 2018, doi: 10.4018/JOEUC.2018070101.

[5] M. Suleman, T. R. Soomro, T. M. Ghazal, and M. Alshurideh, "Combating Against Potentially Harmful Mobile Apps," in Proceedings of the International Conference on Artificial Intelligence and Computer Vision (AICV2021), Jun. 2021, pp. 154-173. doi: 10.1007/978-3-030-76346-6_15.

[6] M. Hassanalieragh, A. Page, T. Soyata, G. Sharma, M. Aktas, G. Mateos, B. Kantarci, and S. Andreescu, "Health Monitoring and Management Using Internet-of-Things (IoT) Sensing with Cloud-Based Processing: Opportunities and Challenges," in Proceedings 2015 IEEE International Conference on Services Computing, SCC 2015, Aug. 2015, pp. 285-292. doi: 10.1109/SCC.2015.47. 
[7] T. M. G. D. K. Mohammed A. M. Afifi, "The Impact of Deploying the Internet of Things and How Will It Change Our Lives," Solid State Technology, vol. 64, no. 2, pp. 20492055, Feb. 2021, Accessed: Nov. 16, 2021. [Online]. Available: https://solidstatetechnology.us/index.php/JSST/article/view/9517

[8] M. Pouryazdan, C. Fiandrino, B. Kantarci, T. Soyata, D. Kliazovich, and P. Bouvry, "Intelligent Gaming for Mobile Crowd-Sensing Participants to Acquire Trustworthy Big Data in the Internet of Things," IEEE Access, vol. 5, pp. 22209-22223, Oct. 2017, doi: 10.1109/ACCESS.2017.2762238.

[9] U. Arun, N. Sriraam, and S. Avvaru, "Study and investigation of continuous cardiac monitoring using vernier EKG with myRIO processor," Sep. 2017. doi: 10.1109/CIMCA.2016.8053314.

[10] M. McCarthy and P. Spachos, "Using mobile environment sensors for wellness monitoring," in IEEE International Workshop on Computer Aided Modeling and Design of Communication Links and Networks, CAMAD, Dec. 2016, pp. 135-139. doi: 10.1109/CAMAD.2016.7790344.

[11] T. M. Ghazal, "Internet of Things with Artificial Intelligence for Health Care Security," Arabian Journal for Science and Engineering 2021, pp. 1-12, Aug. 2021, doi: 10.1007/S13369-021-06083-8.

[12] T. M. Ghazal, M. Anam, M. K. Hasan, M. Hussain, M. S. Farooq, H. M. A. Ali, M. Ahmad, and T. R. Soomro, "Hep-pred: Hepatitis C staging prediction using fine gaussian SVM,” Computers, Materials and Continua, vol. 69, no. 1, pp. 191-203, Jun. 2021, doi: 10.32604/CMC.2021.015436.

[13] A. B. Pawar and S. Ghumbre, "A survey on IoT applications, security challenges and counter measures," in International Conference on Computing, Analytics and Security Trends, CAST 2016, Apr. 2017, pp. 294-299. doi: 10.1109/CAST.2016.7914983.

[14] N. Dimitrioglou, D. Kardaras, and S. Barbounaki, "Multicriteria evaluation of the internet of things potential in health care: The case of dementia care," in Proceedings 2017 IEEE 19th Conference on Business Informatics, CBI 2017, Aug. 2017, vol. 1, pp. 454-462. doi: 10.1109/CBI.2017.34. 
[15] M. K. Hasan, T. M. Ghazal, A. Alkhalifah, K. A. Abu Bakar, A. Omidvar, N. S. Nafi, and J. I. Agbinya, "Fischer Linear Discrimination and Quadratic Discrimination Analysis-Based Data Mining Technique for Internet of Things Framework for Healthcare," Frontiers in Public Health, vol. 9, p. 1354, Oct. 2021, doi: 10.3389/FPUBH.2021.737149/BIBTEX.

[16] T. M. Ghazal, "Positioning of UAV Base Stations Using 5G and Beyond Networks for IoMT Applications," Arabian Journal for Science and Engineering, 2021, doi: 10.1007/s13369-021-05985-x.

[17] R. Bibi, Y. Saeed, A. Zeb, T. M. Ghazal, T. Rahman, R. A. Said, S. Abbas, M. Ahmad, and M. A. Khan, "Edge AI-Based Automated Detection and Classification of Road Anomalies in VANET Using Deep Learning," Computational Intelligence and Neuroscience, vol. 2021, Sep. 2021, doi: 10.1155/2021/6262194.

[18] S. Tayeb, S. Latifi, and Y. Kim, “A survey on IoT communication and computation frameworks: An industrial perspective," Mar. 2017. doi: 10.1109/CCWC.2017.7868354.

[19] R. Naqvi, T. R. Soomro, H. M. Alzoubi, T. M. Ghazal, and M. T. Alshurideh, "The Nexus Between Big Data and Decision-Making: A Study of Big Data Techniques and Technologies," in Proceedings of the International Conference on Artificial Intelligence and Computer Vision (AICV2021), Jun. 2021, pp. 838-853. doi: 10.1007/978-3-03076346-6_73.

[20] S. M. R. Islam, M. Hossain, R. Hasan, and T. Q. Duong, "A conceptual framework for an IoT-based health assistant and its authorization model," in 2018 IEEE 8th Annual Computing and Communication Workshop and Conference, CCWC 2018, Feb. 2018, vol. 2018-January, pp. 616-621. doi: 10.1109/CCWC.2018.8301670.

[21] S. Y. Siddiqui, A. Haider, T. M. Ghazal, M. A. Khan, I. Naseer, S. Abbas, M. Rahman, J. A. Khan, M. Ahmad, M. K. Hasan, A. Mohammed. A, and K. Ateeq, "IoMT CloudBased Intelligent Prediction of Breast Cancer Stages Empowered With Deep Learning," IEEE Access, vol. 9, pp. 146478-146491, Oct. 2021, doi: 10.1109/ACCESS.2021.3123472. 
[22] Y. Yamada, T. Saito, S. Kawasaki, D. Iketa, M. Katagiri, M. Nishimura, and H. Mineno, “A Deep-Learning-Based Method of Estimating Water Intake," in Proceedings - International Computer Software and Applications Conference, Sep. 2017, vol. 2, pp. 96-101. doi: 10.1109/COMPSAC.2017.14.

[23] S. Verma, Y. Kawamoto, Z. M. Fadlullah, H. Nishiyama, and N. Kato, “A Survey on Network Methodologies for Real-Time Analytics of Massive IoT Data and Open Research Issues," IEEE Communications Surveys and Tutorials, vol. 19, no. 3, pp. 1457-1477, Jul. 2017, doi: 10.1109/COMST.2017.2694469.

[24] B. Maradani and H. Levkowitz, "The role of visualization in tele-rehabilitation: A case study," in Proceedings of the 7th International Conference Confluence 2017 on Cloud Computing, Data Science and Engineering, Jun. 2017, pp. 643-648. doi: 10.1109/CONFLUENCE.2017.7943231.

[25] S. I. Lakkis and M. Elshakankiri, "IoT based emergency and operational services in medical care systems," in Joint 13th CTTE and 10th CMI Conference on Internet of Things - Business Models, Users, and Networks, Nov. 2017, vol. 2018-January, pp. 15. doi: 10.1109/CTTE.2017.8260983.

[26] A. Page, T. Soyata, J.-P. Couderc, M. Aktas, B. Kantarci, and S. Andreescu, "Visualization of Health Monitoring Data Acquired from Distributed Sensors for Multiple Patients," in 2015 IEEE Global Communications Conference (GLOBECOM), Mar. 2015, pp. 1-7. doi: 10.1109/GLOCOM.2015.7417414.

[27] N. Powers, A. Alling, K. Osolinsky, T. Soyata, M. Zhu, H. Wang, H. Ba, W. Heinzelman, J. Shi, and M. Kwon, "The cloudlet accelerator: Bringing mobile-cloud face recognition into real-time,” Dec. 2015. doi: 10.1109/GLOCOMW.2015.7414055.

[28] M. Ha and T. Lindh, "Distributed performance management of Internet of Things as a service for caregivers," in 2017 IEEE 19th International Conference on e-Health Networking, Applications and Services, Healthcom 2017, Dec. 2017, vol. 2017December, pp. 1-6. doi: 10.1109/HEALTHCOM.2017.8210765.

[29] A. M. Njeru, M. S. Omar, and S. Yi, "IoTs for capturing and mastering massive data online learning courses," in 16th IEEE/ACIS International Conference on Computer and 
Information Science, ICIS 2017, Jun. 2017, pp. 91-94. doi: 10.1109/ICIS.2017.7959975.

[30] M. Chengathir Selvi, T. D. Rajeeve, A. J. P. Antony, and T. Prathiba, "Wireless sensor based healthcare monitoring system using cloud," Oct. 2017. doi: 10.1109/ICISC.2017.8068710.

[31] A. M. Khairuddin, K. N. F. Ku Azir, and P. E. Kan, "Limitations and future of electrocardiography devices: A review and the perspective from the Internet of Things," Aug. 2017. doi: 10.1109/ICRIIS.2017.8002506.

[32] P. Svoboda, T. M. Ghazal, M. A. M. Afifi, D. Kalra, M. T. Alshurideh, and H. M. Alzoubi, "Information Systems Integration to Enhance Operational Customer Relationship Management in the Pharmaceutical Industry," in Proceedings of the International Conference on Artificial Intelligence and Computer Vision (AICV2021), Jun. 2021, pp. 553-572. doi: 10.1007/978-3-030-76346-6_50.

[33] M. K. H. R. H. , S. I. S. N. H. S. A., M. A. M. A. , D. K. Taher M. Ghazal, "Security Vulnerabilities, Attacks, Threats and the Proposed Countermeasures for the Internet of Things Applications," Solid State Technology, vol. 63, no. 1s, pp. 2513-2521, Oct. 2020, Accessed: Nov. 16, 2021. [Online]. Available: https://solidstatetechnology.us/index.php/JSST/article/view/3096

[34] H. N. Dai, Z. Zheng, and Y. Zhang, "Blockchain for Internet of Things: A Survey," IEEE Internet of Things Journal, vol. 6, no. 5, pp. 8076-8094, Oct. 2019, doi: 10.1109/JIOT.2019.2920987.

[35] M. A. M. A. D. K. Taher M. Ghazal, "Data Mining and Exploration: A Comparison Study among Data Mining Techniques on Iris Data Set," Journal of Talent Development and Excellence, vol. 12, no. 1, pp. 3854 - 3861-3854 - 3861, Jun. 2020, Accessed: Nov. 16, 2021. [Online]. Available: https://www.iratde.com/index.php/jtde/article/view/1339

[36] T. M. Ghazal, R. A. Said, and N. Taleb, "Internet of vehicles and autonomous systems with AI for medical things," Soft Computing, pp. 1-13, Jul. 2021, doi: 10.1007/S00500021-06035-2/TABLES/5. 
[37] K. al Shebli, R. A. Said, N. Taleb, T. M. Ghazal, M. T. Alshurideh, and H. M. Alzoubi, 'RTA's Employees' Perceptions Toward the Efficiency of Artificial Intelligence and Big Data Utilization in Providing Smart Services to the Residents of Dubai," in Proceedings of the International Conference on Artificial Intelligence and Computer Vision (AICV2021), Jun. 2021, pp. 573-585. doi: 10.1007/978-3-030-76346-6_51.

[38] Y. Zhang, G. Chen, H. Du, X. Yuan, M. Cheriet, and M. Kadoch, "Real-Time Remote Health Monitoring System Driven by 5G MEC-IoT," Electronics, vol. 9, no. 11, p. 1753, Oct. 2020, doi: 10.3390/ELECTRONICS9111753.

[39] S. v. Zanjal and G. R. Talmale, "Medicine Reminder and Monitoring System for Secure Health Using IOT,” Procedia Computer Science, vol. 78, pp. 471-476, Jan. 2016, doi: 10.1016/J.PROCS.2016.02.090.

[40] M. N. Bhuiyan, M. M. Rahman, M. M. Billah, and D. Saha, "Internet of Things (IoT): A Review of Its Enabling Technologies in Healthcare Applications, Standards Protocols, Security, and Market Opportunities," IEEE Internet of Things Journal, vol. 8, no. 13, pp. 10474-10498, Jul. 2021, doi: 10.1109/JIOT.2021.3062630.

[41] F. Ullah, M. A. Habib, M. Farhan, S. Khalid, M. Y. Durrani, and S. Jabbar, "Semantic interoperability for big-data in heterogeneous IoT infrastructure for healthcare," Sustainable Cities and Society, vol. 34, pp. 90-96, Oct. 2017, doi: 10.1016/J.SCS.2017.06.010.

[42] F. Matloob, T. M. Ghazal, N. Taleb, S. Aftab, M. Ahmad, M. A. Khan, S. Abbas, and T. R. Soomro, "Software defect prediction using ensemble learning: A systematic literature review," IEEE Access, vol. 9, pp. 98754-98771, Jul. 2021, doi: 10.1109/ACCESS.2021.3095559.

[43] K. Jayavel, V. Nagarajan, and G. Sharma, "An analysis of IOT test beds with application in the field of medicine and health care," Research Journal of Pharmacy and Technology, vol. 10, no. 12, pp. 4155-4161, Dec. 2017, doi: 10.5958/0974360X.2017.00757.0. 
[44] J. Huang, X. Wu, W. Huang, X. Wu, and S. Wang, "Internet of things in health management systems: A review," International Journal of Communication Systems, vol. 34, no. 4, p. e4683, Dec. 2020, doi: 10.1002/DAC.4683.

[45] J. S. Mboli, D. K. Thakker, and J. L. Mishra, “An Internet of Things-enabled decision support system for circular economy business model," Software: Practice and Experience, pp. 1-16, Apr. 2020, doi: 10.1002/SPE.2825.

[46] M. Sathya, S. Madhan, and K. Jayanthi, "Internet of things (IoT) based health monitoring system and challenges," International Journal of Engineering \& Technology, vol. 7, no. 1.7, pp. 175-178, Feb. 2018, doi: 10.14419/ijet.v7i1.7.10645.

[47]. Mehmood, T., Alzoubi, H, Alshurideh, M., Al-Gasaymeh, A., \&Ahmed, G. (2019). Schumpeterian Entrepreneurship Theory: Evolution and Relevance. Academy of Entrepreneurship Journal, 25(4). 1-10, doi.org/10.1080/13662716.2016.1216397

[48]. Alzoubi, H., Ahmed, G., Al-Gasaymeh, A., \& Alkurdi, B. (2019). Empirical study on Sustainable Supply Chain Strategies and its impact on Competitive Priorities: The mediating role of Supply Chain Collaboration. Management Science Letters, 10(3), 703-708, doi.org/10.5267/j.msl.2019.9.008

[49]. Alzoubi, H. \& Ahmed, G. (2019). Do Total Quality Management (TQM) Practices Improve Organisational Success? A case study of electronics industry in the UAE. International Journal of Economics and Business Research, 17(4), 459-472, doi.org/10.1504/IJEBR.2019.099975

[50]. Al-Gasaymeh, A., Ahmed, G., Mehmood, T. \& Alzoubi, H. (2019). CoIntegration Tests and the Long-Run Purchasing Power Parity: A Case Study of India and Pakistan Currencies. Theoretical Economics Letters, 9(4), 570-583.

[51]. Alzoubi, H., Abdo M., Al-Gasaymeh, A. \& Alzoubi, A. (2019). An empirical study of e-Service quality and its impact on achieving a value added. Journal of Business and Retail Management Research (JBRMR), 13(4), 138-145.

[52]. Alzoubi, H. (2018). The Role of Intelligent Information System in e-Supply Chain Management Performance. International Journal of Multidisciplinary Thought, 7(2), 363-370.

[53]. Alzoubi, A., Al-Gasaymeh, A., \& Alzoubi, H. (2018). The Impact of Changes in the Qualitative Characteristics of Accounting Information on the Quality of 
Investment Decisions: A Field Study in the Brokerage Offices. The Journal of Economic and Management Perspectives (JEMP), 12(4), 67-82.

[54]. Alnazer, N., Alnuaimi, M. \& Alzoubi, H. (2017). Analyzing the Appropriate Cognitive Styles and its effect on Strategic Innovation in Jordanian Universities. International journal of business excellence, 13(1), 127-140, doi.org/10.1504/IJBEX.2017.085799

[55]. Khafajy, N., Alzoubi, H. \& Aljanabee, A. (2016). Analyzing the effect of knowledge management processes in the services' quality in Iraqi commercial banks. International Review of Management and Business Research, 5(1), 302-314.

[56]. Alzoubi, H., Alnazer, N. \& Alzoubi, A. (2016). Exploring the Impact of the use of Business Information systems BIS on the organizational performance effectiveness. International Journal of Business and Management Invention, 5(4), 48-55.

[57]. Alnuaimi, M., Alzoubi, H., Alzubi, A. \& AL-Shinewi, M. (2015). The Impact of Managers Efficiency on Quality of Strategic Decision-making under Crisis Management. European Journal of Business and Management, 7(26), 156-166.

[58]. Alrubaiee, L., Alzubi, H., Hanandeh, R. \& Ali, R. (2015). Investigating the Relationship between Knowledge Management Processes and Organizational Performance: The Mediating Effect of Organizational Innovation. International Review of Management and Business Research, 4(4), 977-997

[59]. Alzoubi, H. \& Khafajy, N. (2015). The Impact of Business Process Management on Business Performance Superiority. International Journal of Business and Management Review, 3(2), 17-34

[60]. Alzubi, H., Mohammad, S. \& Abu-salma, A. (2015). Evaluating Strategic Quality Management Dimensions Using Analytic Hierarchy Process (AHP) and its Impact on Organizational Success. International Journal of Research in Management, $5(1), 137-150$.

[61]. Mohammad, S., Abu-salma, A. \& Alzoubi, H. (2015). American Muslims' Perceptions Toward Transforming Islamic Banking System. International Journal of Economics, Commerce and Management, 5(1), 1-16.

[62]. Alrubaiee, L., Al zuobi, H. \& Abu-Alwafa, R. (2013). Exploring the Relationship between Quality Orientation, New Services Development and Organizational Performance. American Academic \& Scholarly Research Journal, 5(3), 315-329. 
[63]. Alzoubi, H. \& Khafajy, N. (2010). Analyze the Impact of Managers Awareness of Environmental Uncertainty on Exploiting Strategic Competencies. Egyptian Journal for Commercial Studies, 34(2), 611-625.

[64]. Al-zu'bi, H. (2010). Applying Electronic Supply Chain Management Using Multi-Agent System: A Managerial Perspective. International Arab Journal of eTechnology, 1(3), 106-113.

[65]. Alnuaimi, M., Alzoubi, A. \& Alzoubi, H. (2010). Propose a model for Performance Criteria and measuring its impact for Achieving Excellence. Association of Arab Universities Journal, 56(4), 920-941.

[66]. Aziz, N., \& Aftab, S. (2021). Data Mining Framework for Nutrition Ranking: Methodology: SPSS Modeller. International Journal of Technology, Innovation and Management (IJTIM), 1(1), 85-95.

[67]. Radwan, N., \& Farouk, M. (2021). The Growth of Internet of Things (IoT) In The Management of Healthcare Issues and Healthcare Policy Development. International Journal of Technology, Innovation and Management (IJTIM), 1(1), 69-84.

[68]. Cruz, A. (2021). Convergence between Blockchain and the Internet of Things. International Journal of Technology, Innovation and Management (IJTIM), 1(1), 34-53.

[69]. Lee, C., \& Ahmed, G. (2021). Improving IoT Privacy, Data Protection and Security Concerns. International Journal of Technology, Innovation and Management (IJTIM), 1(1), 18-33.

[70]. Alzoubi, A. (2021) The impact of Process Quality and Quality Control on Organizational Competitiveness at 5-star hotels in Dubai. International Journal of Technology, Innovation and Management (IJTIM). 1(1), 54-68

[71]. Al Ali, A. (2021). The Impact of Information Sharing and Quality Assurance on Customer Service at UAE Banking Sector. International Journal of Technology, Innovation and Management (IJTIM), 1(1), 01-17.

[72]. Kashif, A. A., Bakhtawar, B., Akhtar, A., Akhtar, S., Aziz, N., \& Javeid, M. S. (2021). Treatment Response Prediction in Hepatitis C Patients using Machine Learning Techniques. International Journal of Technology, Innovation and Management (IJTIM), $1(2), 79-89$.

[73]. Akhtar, A., Akhtar, S., Bakhtawar, B., Kashif, A. A., Aziz, N., \& Javeid, M. S. (2021). COVID-19 Detection from CBC using Machine Learning 
Techniques. International Journal of Technology, Innovation and Management (IJTIM), 1(2), 65-78.

[74]. Eli, T. (2021). StudentsPerspectives on the Use of Innovative and Interactive Teaching Methods at the University of Nouakchott Al Aasriya, Mauritania: English Department as a Case Study. International Journal of Technology, Innovation and Management (IJTIM), 1(2), 90-104.

[75]. Alsharari, N. (2021). Integrating Blockchain Technology with Internet of things to Efficiency. International Journal of Technology, Innovation and Management (IJTIM), 1(2), 01-13.

[76]. Mehmood, T. (2021). Does Information Technology Competencies and Fleet Management Practices lead to Effective Service Delivery? Empirical Evidence from ECommerce Industry. International Journal of Technology, Innovation and Management (IJTIM), 1(2), 14-41.

[77]. Miller, D. (2021). The Best Practice of Teach Computer Science Students to Use Paper Prototyping. International Journal of Technology, Innovation and Management (IJTIM), 1(2), 42-63. 